\title{
The Effects of Modifying the Distance of the Penalty Shot in Water Polo
}

\author{
by \\ Francisco Manuel Argudoㅁ, Roberto Ruiz-Barquín², Pablo José Borges ${ }^{3}$
}

The aim of this study was to determine the effects of changing the distance of the penalty shot in water polo from 4 to $5 \mathrm{~m}$. While a shorter distance made the penalty shot more effective, it also reduced the use of this sanction. A total of 192 matches played in the 2003 and 2007 Water Polo World Championships were recorded. The sample included 278 penalty shots in both tournaments. Notational analysis using a longitudinal correlational and descriptive design was employed to determine whether a longer distance increased the number of sanctioned penalties (81 vs 197) and caused a non-significant decrease in scoring efficiency (7.4\%) with significant differences in the relationship between the area and the type of a shot, with less centre and power shots (14.8\% vs $7.1 \%$ ) observed and predominance of bounce shots to the right of the goal posts. The rule change prompted more penalties, produced changes in shot direction as well as the type of a shot, and yielded a decrement of $7.4 \%$ in scoring efficiency.

Key words: water polo, rules modification, penalty shot..

\section{Introduction}

Water polo first emerged in the United Kingdom at the end of the 19th century as an alternative to football during the summer months, and it was the first Olympic team sport. This young sport discipline has undergone major changes to its rules over time since the first official regulations in 1876; the changes are ongoing, with the latest amendments made by the International Amateur Swimming Federation (FINA) in 2013. These changes have led to the emergence of three very distinct stages in the game.

Scientific interest in water polo tends to focus on physiological (Kavouras et al., 2006; Platanou and Geladas, 2006; Tsekouras et al., 2005), psychological (Marlow et al., 1998; Thanopoulos, 2006), bio-mechanical (Elliot, 1988; Feltner and Nelson, 1996; Feltner and Taylor, 1997) and technical/tactical aspects (Argudo et al., 2007; Platanou, 2004; Smith, 2004). There has been a surge in interest in the technical/tactical aspect in recent years due to its influence on performance (Argudo et al., 2008). In particular, in recent years, technical and tactical studies of this sport have been focused on team efficacy (Argudo et al., 2007, 2008; Lupo et al., 2009), tactical roles (Lozovina et al., 2004; Lupo et al., 2012a), a competition level (Lupo et al., 2010), match outcomes (Argudo et al., 2007, 2009; Lupo et al., 2011; Smith, 2004), and margin of victory (Gomez et al., 2014; Lupo et al., 2012b, 2014).

It is therefore necessary to determine how rule changes related to the distance of the penalty shot from the goal have influenced scoring efficacy and the development of the game itself.

The aim of this study was to understand the effects of changing the distance of the penalty shot in water polo. While a shorter distance made the penalty shot more effective, it reduced the

\footnotetext{
1 - Department of Physical Education, Sport E Human Movement. Autonomous University of Madrid (Spain).

2 - Interfacultative Department of Evolutionary Psychology and Education. Autonomous University of Madrid (Spain).

3 - Department of Physical Education, Sport E Human Movement. Autonomous University of Madrid (Spain).
} 
occurrence of this sanction.

\section{Material and Methods}

\section{Participants}

The study considered all the penalties scored at the 10th Water Polo World Championships held in Barcelona in 2003 and the 12th Water Polo World Championships held in Melbourne in 2007. The sample comprised 278 shots, 95 of which were in the female category (40 in 2003 and 55 in 2007) and 183 in the male category (41 in 2003 and 142 in 2007).

\section{Measures}

Five variables were analysed in this study: (1) Gender, with two categories: male and female; (2) Side, with two categories: right handed and left handed; (3) Shot, with two categories: a straight forward power shot and a bounce shot (or a skip shot); (4) Efficacy, with two categories: goal and no goal; and (5) Goal post area, at which the ball is aimed, with three categories: right lateral, central and left lateral.

\section{Procedures}

Notational analysis (Anguera and Blanco, 2003; Gomez et al., 2014; Lupo et al., 2014) using a longitudinal correlational and descriptive design was employed to determine whether differences occurred due to rule changes. All penalties from each of the games were recorded, using two digital video cameras (JVC, GZ-MG50E, JAPN), positioned in the area behind each goal post. Afterwards, an evaluation of the shots using Polo Direct Analysis v1.0 software (Argudo et al., 2005) was performed by ten independent observers who had received prior training in observational categorisation (Argudo et al., 2005). Inter-observer reliability was assessed using the Kappa concordance index, ensuring concordance coefficients greater than .98 in all cases.

\section{Analysis}

The data registered in Polo Direct Analysis v 1.0 were exported using the SPSS 19.0 statistical package for Windows.

The $\chi^{2}$ test was applied to determine the influence of rule changes regarding the distance of penalty shots. All analyses were completed with respective contingency tables.

\section{Results}

The results obtained based on the objectives of this study are presented below: a) Descriptive analysis of the 2003 and 2007 Championships.

A contingency table (Table 1) displays the frequency and percentages of five variables considered in the corresponding championships in 2003 and 2007. The studied variables were "sex", "laterality", "shot type", "efficacy" and "goal post area". As shown in Table 1, in the 2003 Championships, the percentages of female and male athletes were almost equal, with an increased number of shots from right-handed players, a higher percentage of power shots, a higher percentage of shots resulting in goals $(81.5 \%)$ and a lower percentage of shots resulting from shots at the centre of the goal post compared to those taken from the side. In contrast, there was a higher frequency of male than female athletes in the 2007 World Championships compared to 2003, with nearly equal percentages of shots by righthanded and left-handed players, higher percentages of "power shots" than "bounce shots" and higher percentages of shots to the right side of the goal post compared to the centre or the left side.

When we compared the frequency of the occurrence of studied variables selected from both championships, differences were found in all variables except for the laterality of the players. The number of shots more than doubled from the championships in 2003 to 2007, from 81 to 197, respectively. There was a shift from an equal number of penalties by each gender in 2003, to the preponderance of penalties in the men's competition (72.1\%) in 2007. Although a 15\% decrease in power shots was observed in 2007, it remained the most widely used, with $61.4 \%$ of shots of this type performed. There was a decrease in shots taken from the centre and lefthand side of the goal post and an increase in shots from the right-hand side. Lastly, there was a 7.4\% decrease in scoring efficacy in the 2007 World Championships.

b) Determination of efficacy differences between the two championships.

The results demonstrate very similar ratios between the two championships. The $\chi^{2}$ test pinpoints lack of any significant difference between the efficacy ratios in both championships $\left(\chi^{2}=1.722 ; p=.189\right)$.

In the absence of any significant differences, we considered the gender variable based on the 
differences (in percentages) between the results of male and female athletes in the 2007 Championship (Table 1) and the 2003 Championship. By applying the $\chi^{2}$ test, significant differences $\left(\chi^{2}=11.755 ; p<.001\right)$ were found in gender variable ratios, which points to the need to perform differential statistical analyses controlling for this variable.

The results of the relationship between efficacy and the championship analysed in the men's category did not show any statistically significant results $\left(\chi^{2}=2.619, p=.106\right)$. Similarly, the results in the women's category showed an absence of any significant differences $\left(\chi^{2}=.397 ; p\right.$ $=.528)$. Therefore, there was no difference in the degree of efficacy between the two championships.

c) Determination of differences between the two championships in terms of laterality.

The application of the $\chi^{2}$ test found no statistically significant differences between the championships ( $\chi^{2}=.017 ; p=.897$ ).

However, this difference was confirmed when performing the analysis for the men's $\left(\chi^{2}=\right.$
$.060 ; p=.807)$ and women's categories $\left(\chi^{2}=.057 ; p\right.$ $=.811)$. Laterality was greater in right-handed cases than in left-handed ones for both championships.

d) Determination of shot differences between the two championships.

In contrast, significant differences were observed in the shot type $\left(\chi^{2}=5.835 ; p=.016\right)$. The

bounce shot was used more often in the 2007 Championships compared to the 2003 Championships.

To determine whether such an effect occurred in both categories (male and female), the same analyses were conducted for the male group, showing the absence of any significant results $\left(\chi^{2}\right.$ $=.084 ; p=.771)$. However, significant differences were observed in the female category, indicating a significant increase in bounce shots in the 2007 Championship $\left(\chi^{2}=10.586 ; p=.001\right)$.

e) Determination of differences related to the location of the goal post toward which the shots were aimed in the two championships.

Table 1

Analysis of frequency and percentages for the 2003 and 2007 Championships.

\begin{tabular}{lccccc}
\hline \multirow{3}{*}{ Variables } & & \multicolumn{2}{c}{ CHAMPIONSHIP 2003 } & \multicolumn{2}{c}{ CHAMPIONSHIP 2007 } \\
\cline { 3 - 6 } Sex & Male & 41 & 50.6 & 142 & 72.1 \\
& Female & 40 & 49.4 & 55 & 27.9 \\
Side & Total & 81 & 100.0 & 197 & 100 \\
\hline \multirow{4}{*}{ Shot } & Right-handed & 69 & 85.2 & 169 & 85.8 \\
& Left-handed & 12 & 14.8 & 28 & 14.2 \\
\hline \multirow{4}{*}{ Efficacy } & Total & 81 & 100.0 & 197 & 100.0 \\
& Front tense & 62 & 76.5 & 121 & 61.4 \\
& Front & 19 & 23.5 & 76 & 38.6 \\
\hline \multirow{3}{*}{ Gith bounce } & Total & 81 & 100.0 & 197 & 100.0 \\
\hline \multirow{2}{*}{ Goal post } & Goal & 66 & 81.5 & 146 & 74.1 \\
& No goal & 15 & 18.5 & 51 & 25.9 \\
& Total & 81 & 100.0 & 197 & 100.0 \\
\hline & Right lateral & 24 & 29.6 & 78 & 39.6 \\
& Central & 12 & 14.8 & 14 & 7.1 \\
& Left lateral & 30 & 37.0 & 54 & 27.4
\end{tabular}




\begin{tabular}{|c|c|c|c|c|c|}
\hline \multicolumn{6}{|c|}{$\begin{array}{c}\text { Table } 2 \\
\text { Contingency table based on the championship and effectiveness } \\
\text { as well as the championship and laterality. }\end{array}$} \\
\hline \multirow[b]{2}{*}{ Variables } & & \multicolumn{2}{|c|}{ CHAMPIONSHIP 2003} & \multicolumn{2}{|c|}{ CHAMPIONSHIP 2007} \\
\hline & & Frequency & Percentage & Frequency & Percentage \\
\hline \multirow{3}{*}{ Efficacy } & Goal & 66 & 81.5 & 146 & 74.1 \\
\hline & No goal & 15 & 18,5 & 51 & 25.9 \\
\hline & Total & 81 & 100.0 & 197 & 100 \\
\hline \multirow[t]{3}{*}{ Side } & $\begin{array}{c}\text { Right } \\
\text { handed }\end{array}$ & 69 & 85.2 & 169 & 85.8 \\
\hline & Left handed & 12 & 14.8 & 28 & 14.2 \\
\hline & Total & 81 & 100.0 & 197 & 100.0 \\
\hline
\end{tabular}

\begin{tabular}{|c|c|c|c|c|c|}
\hline \multicolumn{6}{|c|}{$\begin{array}{l}\text { Table } 3 \\
\text { Contingency table based on the championship and the type of a shot and the } \\
\text { championship as well as the place of the goal where the shot occurred. }\end{array}$} \\
\hline \multirow[b]{2}{*}{ Variables } & & \multicolumn{2}{|c|}{ CHAMPIONSHIP 2003} & \multicolumn{2}{|c|}{ CHAMPIONSHIP 2007} \\
\hline & & Frequency & Percentage & Frequency & Percentage \\
\hline \multirow{3}{*}{ Shot } & Front tense & 62 & 76.5 & 121 & 61.4 \\
\hline & Front with bounce & 19 & 23.5 & 76 & 38.6 \\
\hline & Total & 81 & 100.0 & 197 & 100 \\
\hline \multirow{3}{*}{$\begin{array}{l}\text { Shot } \\
\text { (female category) }\end{array}$} & Front tense & 35 & 87.5 & 31 & 56.4 \\
\hline & Front with bounce & 5 & 12.5 & 24 & 43.6 \\
\hline & Total & 40 & 100.0 & 55 & 100.0 \\
\hline \multirow{5}{*}{ Goal Post } & Right lateral & 24 & 29.6 & 78 & 39.6 \\
\hline & Central & 12 & 14.8 & 14 & 7,1 \\
\hline & Left lateral & 30 & 37,0 & 54 & 27,4 \\
\hline & Without goal & 15 & 18,5 & 51 & 25,9 \\
\hline & Total & 81 & 100.0 & 197 & 100.0 \\
\hline
\end{tabular}

The results of this analysis were statistically significant $\left(\chi^{2}=8.273 ; p=.041\right)$. There was an increase in "right lateral" shots and a reduction in both the "central" and "left lateral" areas in the 2007 Championships. There was also a slight increase in "no goal" shots.

In this case, it was impossible to conduct an analysis based on the gender variable because the requirements of the $\chi^{2}$ test were not met, as there was an insufficient number of frequencies or cases in the contingency tables developed for both the male and female categories. Therefore, the results show significant differences in the goal post location where the shot was performed when comparing the two championships.

\section{Discussion}

This study aimed to analyse the influence of changes made to the penalty shot distance of 4 $\mathrm{m}$ in 2003 and $5 \mathrm{~m}$ in 2007, and the influence of these changes on scoring efficacy. A high level of efficacy in these shots can influence the final result of the match due to their importance to the game (Mirviê et al., 2011).

The few studies based on real games (Lupo et al., 2012a, b, 2014) only highlighted the increase in the number of sanctioned penalties and showed that significant differences existed in 
their occurrence among the teams that won more than their three-goal games.

In the 2003 World Championships, the same percentage of penalties considering the gender variable was performed. However, in 2007 , this percentage increased in male water polo (72.1\%). This is because ball possession time decreased by five seconds, which resulted in a faster game, with more playing situations on a counterattack that caused more simple temporary numerical inequalities or penalties.

In the 2007 World Championships, the percentage of "power shots" (15\%) decreased, although it still remained the type of a shot the most often used $(61.4 \%)$. There was also an increase in shots directed to the right side of the goal post and a decrease in shots to the centre or the left side. In addition, a slight increase of "no goal" shots was recorded. Considering the change in the distance and the difficulty of surprising the goalkeeper with a quick shot, it appears that this type of a shot has been replaced with a "bounce shot" directed at the sides of the goal post, making it difficult to stop, which increases the likelihood of scoring a goal, as the scoring efficiency decreased by $7.4 \%$ (although the difference was not significant).

There are very few studies available on the analysis of general scoring efficacy or on penalties in sport, with none whatsoever focusing on water polo. While some studies have been conducted on the accuracy and speed of shots performed under experimental conditions, none have analysed actual play. Van Der Wende (2005) included defenders and goalkeepers in his experiment conducted under semi-real game conditions based on 2003 rules and observed a greater decrease in scoring efficacy as the experimental conditions become similar to the actual game. Scoring efficacy of $66.6 \%$ was found for penalties, which is a lower value than $81.5 \%$ observed in our study, most likely because the sample was composed of regional Australian players. However, she also observed the same pattern of shots taken from the right side. Another study (Escalante et al., 2011) conducted with no direct observation of the 2007 rules, once again identified lower scoring efficacy, except for the male winning teams, who displayed efficacy of $78.5 \%$, what is $4.4 \%$ higher than what we observed. In contrast, Hayley et al. (2010) pointed toward fatigue, accuracy and speed of the shot as influential factors in scoring efficacy, leading researchers to focus on these aspects from a biomechanical perspective (Vila et al., 2009). These authors found no difference between shooting speed from $5 \mathrm{~m}$ with and without the presence of a goalkeeper, and the prior trajectory. It allows us to cautiously compare our results with studies conducted under laboratory conditions. However, it is important to note that while Alcaraz et al. (2011) found that elite players modified their shot pattern and speed depending on whether they were in training or competition conditions, a previous study did not observe such a difference. Therefore, it is impossible to compare our results with previous studies because of conflicting results, as well as the fact that these were performed under experimental conditions and did not consider analysis of a real game.

Royal et al. (2006), examining the influence of fatigue, found that there was less accuracy in shots taken during rest or under less tiring conditions compared to when they were taken after a moderate or vigorous exertion. This provides us with a clue to why there is a decrease in goals scored under the new rules, as penalties are taken throughout the whole game rather than just at the end, when more of these types of offenses were committed with the previous rules in effect.

With this in mind, it would seem relevant, similarly to the case of free throws in basketball (Arias et al., 2012), to establish such statistics to be considered for future studies, as well as to determine possible relationships between overall scoring and penalties efficacy.

\section{Conclusions}

Based on the objectives of the study and the results obtained, the following game tendencies can be summarized:

- A direct and positive relationship between increased shooting distance and the number of penalties established by referees (81 in 2003 and 197 in 2007), increasing their influence on the final result.

- A direct and negative relationship between scoring efficacy (a 7.4\% decrease) and increased shooting distance.

- A significant difference in relation to the area and the type of a shot based on the distance 
itself. The greater the distance, the fewer the centre and power shots observed, with a predominance of bounce shots to the right of the goal posts.

- No significant differences existed between the lateral dominance of the player with regard to shooting distance. We observed a predominance of right-handed over left-handed players.
- The number of penalties performed in 2003 differed between genders; the great majority of penalties called in 2007 occurred in the men's competition $(72.1 \%)$. However, the difference between the gender penalty sanction was not significant.

\section{References}

Alcaraz PE, Abraldes JA, Ferragut C, Rodríguez N, Argudo FM, Vila H. Throwing velocities, anthropometric characteristics, efficacy indices of women's European water polo subchampions. J Strength Cond Res, 2011; 25(11): 3051-3058

Anguera MT, Blanco A. Registration and codification of sportsmanship, 2003. In A. Hernández-Mendo, Sport Psychology. (Vol. II): Methodology (pp.6-34). Buenos Aires: Tulio Guterman. Available at: http://www.efdeportes.com; accessed on: 01.08.2014

Argudo FM, Alonso JI, Fuentes F. Computerized registration for tactical quantitative evaluation in water polo. Polo partido v1.0. Proceedings of the 5th International Symposium Computer Science in Sport, Hvar: Croatia; 2005

Argudo FM, Ruiz E, Alonso JI. Influence of the efficacy values in numerical equality on the condition of winner or loser in the 2003 Water Polo World Championship. Int J Perf Anal Spor, 2008; 8: 101-112

Argudo FM, Ruiz E, Alonso JI. Were differences in tactical efficacy between the winners and losers teams and the final classification in the 2003 water polo world championship? J of Hum Sport and Exercise, 2009; 4: 142-153

Argudo FM, García P, Alonso JI, Ruiz E. Influence of the efficacy values in counterattack defensive adjustment on the condition of winner loser in male female water polo. Int J Perf Anal Spor, 2007; 7: 8191

Arias JL, Argudo FM, Alonso JI. Effect of basketball mass on shot performance among 9-11 year-old male players. Int J Sports Sci Coa, 2012; 7(1): 69-80

Elliott B. The penalty throw in water polo: A cinematographical analysis. J Sports Sci, 1988; 6: 103-114

Escalante Y, Saavedra JM, Mansilla M, Tella V. Discriminatory power of water polo game-related statistics at the 2008 Olympic Games. J Sports Sci, 2011; 29(3): 291-298

Feltner ME, Nelson ST. Three-dimensional kinematics of the throwing arm during the penalty throw in water polo. J Appl Biomech, 1996; 12: 359-382

Feltner ME, Taylor G. Three-dimensional kinetics of the shoulder, elbow, wrist during a penalty throw in water polo. J Appl Biomech, 1997; 13: 347-372

FINA. Handbook: constitution and rules 2013-2017. Lausanne: Federation Internationale de Natation Amateur; 2013

Gómez MA, DelaSerna A, Lupo C, Sampaio J. Effects of Situational Variables and Starting Quarter Score in the outcome of elite women's water polo game quarters. Int J Perform Anal Sport, 2014; 14(1): 73-83

Hayley B, Stevens HB, Brown LE, Coburn JW, Spiering BA. Effect of swim sprints accuracy velocity water polo players on throwing in female collegiate. J Strength Cond Res, 2010; 24(5): 1195-1198

Kavouras SA, Magkos F, Yannakoulia M, Perraki M, Karipidou M, Sidossis LS. Water polo is associated with an apparent redistribution of bone mass density from the lower to the upper limbs. Eur J Appl Physiol, 2006; 97: 316-321

Lozovina V, Pavicic L, Lozovina M. Analysis of indicators of load during the game in the activity of the center in water polo. Nase More, 2004; 51: 135-141 
Lupo C, Minganti C, Cortis C, Perroni F, Capranica L, Tessitore A. Effects of competition level on the centre forward role of men's water polo. J Sports Sci, 2012a; 30(9): 889-897

Lupo C, Condello G, Tessitore A. Notational analysis of elite men's water polo related to specific margins of victory. J Sport Sci Med, 2012b; 11: 516-525

Lupo C, Condello G, Capranica L, Tessitore A. Women's water polo World Championships: technical and tactical aspects of winning and losing teams in close and unbalanced games. J Strength Cond Res, 2014; 27(1): 210-222

Lupo C, Tessitore A, Cortis C, Ammendolia A, Figura F, Capranica L. A Physiological, Time Motion and Technical Comparison of Youth Water Polo and Acquagoal. J Sports Sci, 2009; 27(8): 823-831.

Lupo C, Tessitore A, Minganti C, King B, Cortis C, Capranica L. Notational analysis of American Women's Collegiate Water polo matches. J Strength Cond Res, 2011; 25(3): 753-757

Marlow C, Bull SJ, Heath B, Shambrook CJ. The use of a single case design to investigate the effect of a preperformance routine on the water polo penalty shot. J Sci Med Sport, 1998; 1: 143-155

Mirviê E, Kazazoviê B, Aleksroviê M. Differences between winning losing teams from World water polo championship for women. Homo Sporticus, Sci J Sport Phys Educ, 2011; 13(2): 38-42

Platanou T. Analysis of the extra man in water polo: A comparison between winning losing teams players of different playing position. J Hum Movement Studies, 2004; 46: 205-211

Platanou T, Geladas N. The influence of competitiveness on match exercise intensity in elite water polo players. Revista Portuguesa de Ciências do Desporto, 2006; 6: S163-S165

Royal KA, Farrow D, Mujica I, Halson S, Pyne D, Abernethy B. The effects of fatigue on decision making shoting skill performance in water polo players. J Sports Sci, 2006; 24(8): 807-815

Sampaio J, Janeira M, Ibáñez S, Lorenzo A. Discriminant analysis of game-related statistics between basketball guards, forwards centres in three professional leagues. Eur J Sport Sci, 2006; 6(3): 173-178

Smith HK. Penalty shot importance, success game context in international water polo. J Sci Med Sport, 2004; 7: 221-225

Thanopoulos V. State of pre-competitive anxiety among swimmers waterpolo players in relation to competitive experience. Revista Portuguesa de Ciências do Desporto, 2006; 6; S343-S346

Tsekouras YE, Kavouras SA, Campagna A, Kotsis YP, Syntosi SS, Papazoglou K, Sidossis LS. The anthropometrical physiological characteristics of elite water polo players. Eur J Appl Physiol, 2005; 95: 35-41

Van Der Wende K. The effects of game-specific task constraints on the outcome of the water polo shot. (PhD thesis) University of Technology, Auckland, New Zeland; 2005. Available at: http://aut.researchgateway.ac.nz/bitstream/handle/10292/98/vanderWendeK.pdf?sequence=2; accessed on: 07.07.2016

Vila H, Ferragut C, Argudo FM, Abraldes JA, Rodríguez N, Alacid F. Relationship between anthropometric parameters throwing velocity in water polo players. J Hum Sport Exerc, 2009; 4(1): 57-68

\section{Corresponding author:}

\section{Francisco Manuel Argudo Iturriaga}

Department of Physical Education, Sport \& Human Movement.

Autonomous University of Madrid (Spain).

Faculty of Teacher Formation and Education

Dispatch: 3 - 322 Campus de Cantoblanco C/Francisco Tomás y Valiente, 328049 Madrid

914972884

E-mail: quico.argudo@uam.es 